\title{
Screen use among young children and parental concern
}

\author{
Silvina B. Pedrouzo, M.D. ${ }^{a}$, Valeria Peskins, M.D. ${ }^{a}$, Ana M. Garbocci, M.D. ${ }^{a}$, \\ Sergio G. Sastre, M.D. ${ }^{a}$ and Jorge Wasserman, M.D. ${ }^{a}$ \\ Collaborators: Laura Krynski, M.D., and Victor D. Podberezski, Engineer
}

\begin{abstract}
Introduction. An excessive technology use among young children is a cause for concern in pediatric practice.

Objective. To assess screen use among children $<4$ years old and its relation to parental concern about psychomotor development regarding motor, language, cognitive, and personal-social skills.

Population and methods. Survey administered to mothers and/or fathers of children aged $\geq 18$ months and $<4$ years seen at the outpatient office between February and May 2018. Descriptive, cross-sectional study.

Results. A total of 150 surveys were completed. Combined device use in $100 \%$ : TV, $98 \%$; smartphones, $80 \%$; tablets, $52.7 \%$; computers, $24 \%$. Average use: $2.25 \mathrm{~h} /$ day across all ages (standard deviation:1.2). Use and quality: games, $60 \%$ (non-educational, $23 \%$ ); videos, $88 \%$ (non-educational, $20 \%$ ). Parental concern about development: $82 \%$ had no concerns; $8.7 \%$ was concerned about language; $9.3 \%$, about attention deficit; thelatter two were consistent with a longer exposure time: $2.92 \mathrm{~h} /$ day $(p=0.0024)$. Parental opinion about use and effects on development: $52 \%$, beneficial; $12 \%$, no effect; $25.3 \%$, harmful; and $10.7 \%$, harmful due to excessive use; the latter two were consistent with a shorter exposure time: $1.8 \mathrm{~h} /$ day $(p=0.0023)$.

Conclusions. The $100 \%$ of children use devices in combination. Parental concern about psychomotor development is expressed when exposure exceeds the current recommendations for age.
\end{abstract}

a. Trade Workers Union Health Insurance Institution, Medrano Clinic, Autonomous City of Buenos Aires. Argentina.

E-mail address:

Silvina B. Pedrouzo, M.D.: silvipedrouzo@gmail.com

Key words: media, mobile devices, child, parents, awareness.

http: / / dx.doi.org/10.5546/ aap.2020.eng.393

To cite: Pedrouzo SB, Peskins V, Garbocci AM, Sastre SG, Wasserman J. Screen use among young children and parental concern. Arch Argent Pediatr 2020;118(6):393-398.

\section{INTRODUCTION}

An excessive use of technology among children younger than 4 years, unsupervised exposure to devices, and potential negative effects on psychomotor development are a cause for concern in pediatric practice. According to Wernicke, the psychomotor development of a child is an evolutionary phenomenon of continuous, progressive skill acquisition, including language, cognitive, motor, social interaction, and behavioral skills, all of which are the product of an interaction between genetic and environmental factors (such as technology use). For this reason, it is critical that, during office visits, pediatricians discuss screen use at an early age and its potential relation to developmental disorders, whose prevalence is increasing $(15.04 \%)^{1}$

It is important to convey the recommendations on screen use made by the Sociedad Argentina de Pediatría and the American Academy of Pediatrics, which advise against screen exposure before 2 years old and to limit its use to 1 hour per day in children aged 2-5 years. Also, during office visits, pediatricians should query about parental concern in relation to child development. ${ }^{2,3}$ A finding of parental concern about child development is a risk indicator ( $80 \%$ of probability of having a disorder) ${ }^{4,5}$

In a recent study, the recommendation was to provide family counseling, in addition to a stronger evidence about the longterm impact of technology use among young children. ${ }^{6}$ It is also advisable 
to promote habits that stimulate children's skills and imagination, e.g., playing outdoors, reading stories, playing with educational toys and with peers. An Argentine study stated that mothers who had completed higher education devote more time to reading to their children. ${ }^{7}$

Sometimes, a young child is left alone using a screen and the playtime necessary to imagine, explore, and bond with others and with the world around them is replaced. The exchange between parents and children during playtime may be influenced by their own attachment to screens.

\section{OBJECTIVE}

To assess screen use among children younger than 4 years and its relation to parental concern about psychomotor development regarding motor, language, cognitive, and personal-social skills.

\section{POPULATION AND METHODS}

This was a cross-sectional study conducted using anonymous surveys administered by the authors to the mother and/or father of children aged between 18 months and 3 years, 11 months, 29 days who had a health checkup appointment at the outpatient clinic of the Trade Workers Union Health Insurance Institution, Medrano Clinic, in the Autonomous City of Buenos Aires (CABA). The study period was from February to May 2018, and participants were selected by consecutive sampling.

The survey was administered upon obtaining a verbal consent and giving a brief explanation about psychomotor development and motor, personal-social, language, and cognitive skills, and the characteristics of educational games and videos (interactive games were defined as those that triggered reactions based on their own actions, had an advanced complexity and promoted joint attention, which entailed the ability to interact with other people and also focus on an object to start a communication; educational videos: songs, stories about animals, jobs, etc.).

The study conduct and publication were approved by the site's Teaching Board and the authorities of the Department of Pediatrics. Twenty pilot surveys were administered to mothers and/or fathers a few days in advance and errors were corrected (see Annex: Survey).

The surveyed population accessed health services through a health plan funded by a labor union and met basic needs (food, housing, sewer system, and drinking water). They also had access to at least one technological device at home.
Google Sheets was used to standardize and plot data; Python, together with Pandas, Numpy, and Pyplot libraries, were used to handle data and plots; and the Epi Info (7.1.4.0) software was used to perform statistical calculations. According to the sample statistical calculation, 149 surveys were required in the studied population, with a $95 \%$ confidence level for an estimated $50 \%$ prevalence of device use.

Studied outcome measures: child's age (months), child's sex (female, male), use time (hours). Dichotomous qualitative values (yes, no) were used to assess daycare attendance; computer, tablet, smartphone, TV use; video or game use; bedtime use; TV on during lunch or dinner; and other activities. Type of videos and games used: educational and non-educational; accompanied use (yes, no, sometimes), caregiver (father, mother, both parents, baby-sitter, other). Parental concern about psychomotor development: yes, no, what about. Parental opinions about use and effects on psychomotor development: beneficial or harmful (yes, no).

Dichotomous qualitative outcome measures were discretized into 0 and 1 for analysis; numerical outcome measures were analyzed by comparing mean and standard deviation (SD) values. Participants were segmented by age and sex to measure impact. The $p$ value was used to establish the validity of hypotheses in relation to two outcome measures.

\section{RESULTS}

A total of 150 surveys were administered consecutively; no one refused to participate. Twenty-eight parents of children aged between 18 months and 23 months, 29 days (18.7\%), and 122 parents of children aged between 2 years and 3 years, 11 months, 29 days $(81.3 \%)$ participated. Among all parents, $83(55.3 \%)$ had a boy and $67(44.7 \%)$, a girl. Eighty-six percent of children attended daycare.

One-hundred percent of children used some of these devices in combination. The most commonly used devices were TV in $98 \%$ (147 children), smartphone in $80 \%$ (120 children), tablet in $52.7 \%$ (79 children), and computer in $24 \%$ (36 children). The daily average screen use in the studied population was 2.25 hours per day $(\mathrm{M}=2.25$; $\mathrm{SD}$ : $1.2 \%$; confidence interval $[\mathrm{CI}]=2.05-2.45$ hours).

Figure 1 shows the number of hours of daily exposure by sex and age. Figure 2 shows the findings about the quality of games and videos content. 
In relation to the use of at least one video or game format, it was observed that 113 children $(75.3 \%)$ used educational and interactive videos and games, and 114 children $(76 \%)$, non-educational ones. Supervision during exposure to videos and games: 74 children (49.3\%) were supervised; 22 (14.7\%) were unsupervised; $40(26.7 \%)$ were sometimes supervised; and $14(9.3 \%)$ did not use any.

Exposure in relation to food and sleep: the TV was on during the main meals in 90 children $(60 \%)$, and $60(40 \%)$ used devices before going to bed. Child caregiver during the day: 94 children $(62.7 \%)$ were looked after by their mother; 38 $(25.3 \%)$, by both parents; and $18(12 \%)$, by baby-sitters and others.
Parental concern about psychomotor development: 123 parents (82\%) did not express any concern; $13(8.7 \%)$ were concerned about language; and $14(9.3 \%)$ were concerned about attention deficit. The two latter statements were consistent with a longer exposure time (2.92 hours / day; $p=0.0024$ ). Parental opinion about screen use and its effects on psychomotor development: 78 parents (52\%) considered it beneficial; 18 (12\%) did not consider it beneficial or harmful; $38(25.3 \%)$ considered it harmful; and $16(10.7 \%)$ thought it was harmful if use was excessive because they answered yes to both options (beneficial and harmful). The two latter parental opinions (harmful and harmful due to

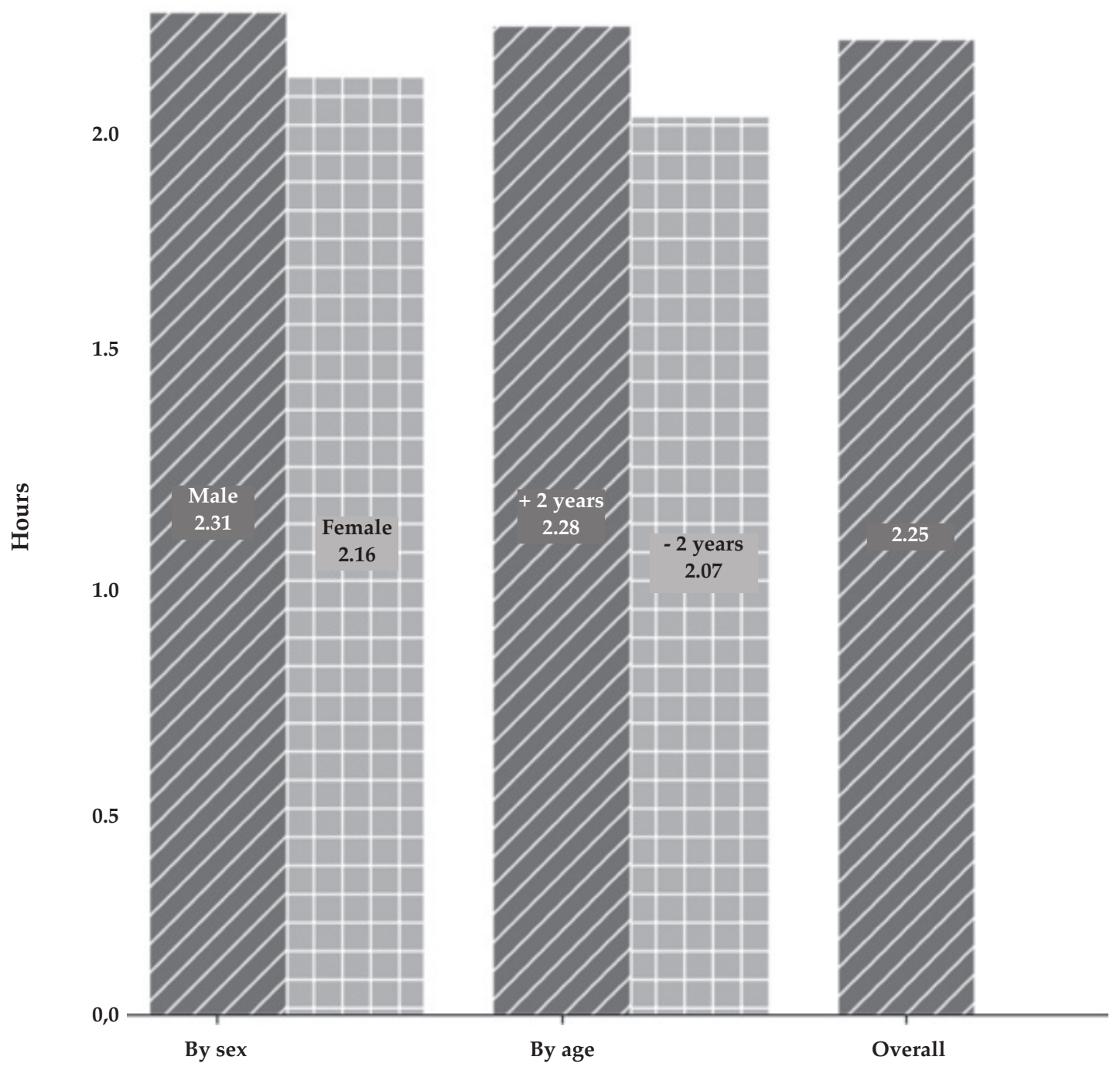


excessive use) included 54 children (36\%) and accounted for those who had a shorter exposure time (1.8 hours / day; $p=0.0023$ ).

\section{DISCUSSION}

The relation that children may establish with technology from an early age and the effects it may have on their development are currently being discussed both in the private setting and in public policies. The new generations are part of a cultural ecosystem, a technological environment (digital natives) where the boundaries between the real and the virtual worlds are becoming more and more blurred. In this context, children make technologies their own based on a cultural immersion experience. ${ }^{8,9}$
As part of the recommendations, the Sociedad Argentina de Pediatría and the American Academy of Pediatrics have proposed to avoid screen exposure in children younger than 18 months because of their immature development and their dependence on adult interactions to decode stimuli; for children younger than 18 months and up to 2 years, the only recommendation is to use applications for live communication with family members. In case of exposure as of 18 months old, children should be accompanied so they can select and interpret content because of the limited evidence of beneficial effects at this age and the replacement of other activities that stimulate child development.

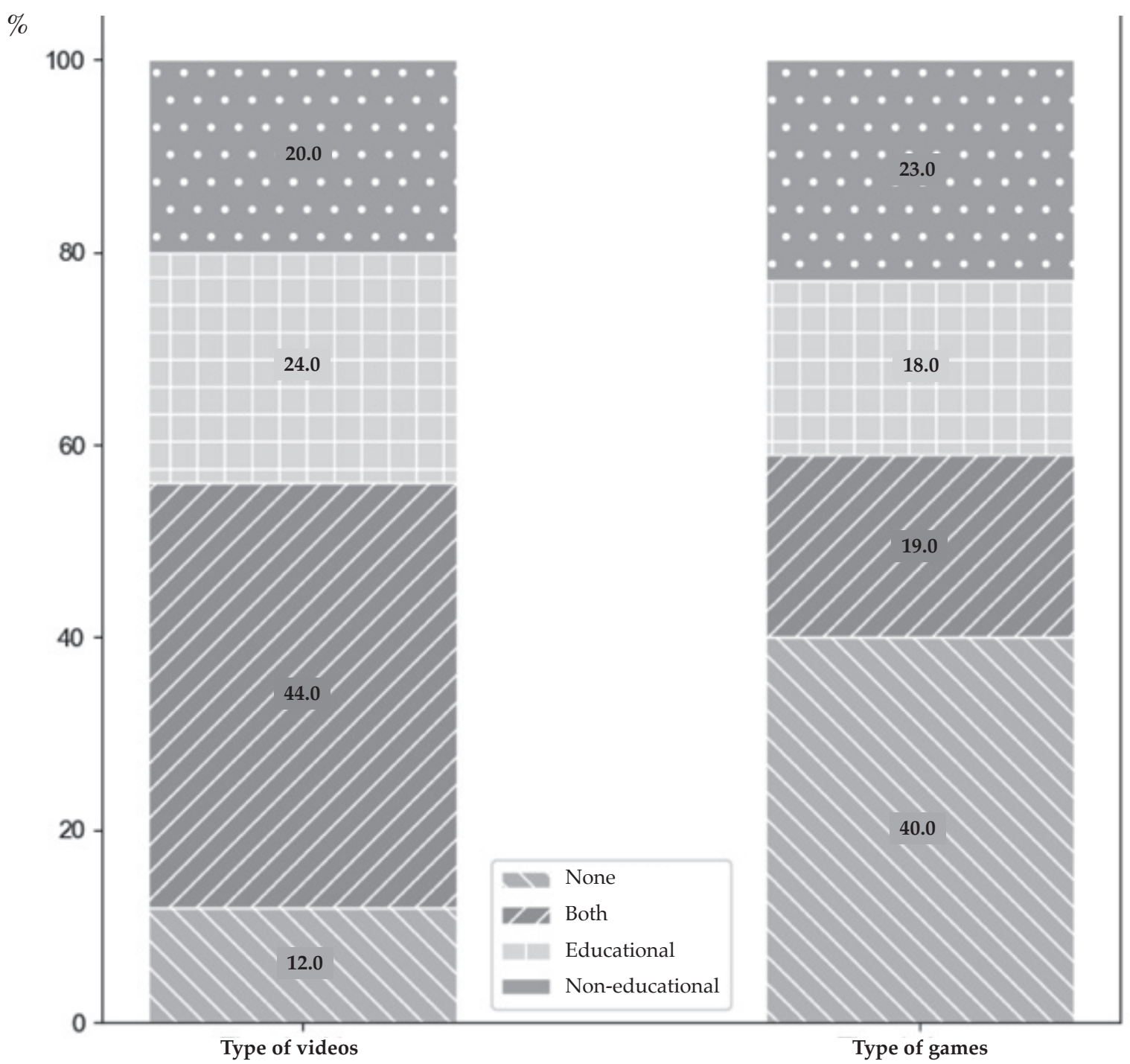


The recommendations for children between 2 and 5 years limit device use to 1 hour per day for educational purposes; a longer exposure may be associated with developmental problems. They also advise against device use before going to bed because it is associated with sleep disorders (lightinduced suppression of endogenous melatonin production) and during the main meals because it may be associated with obesity (exposure to food and beverage advertisement and reduced attention to satiety signals). ${ }^{2,3}$

In our study, the average exposure time was 2.25 hours per day, which exceeded the current recommendations and displaced other activities. Content supervision was observed in less than half of children, together with non-adherence to limitations on use before bedtime and during the main meals.

A recent Argentine study described the disagreement between current recommendations on screen use and actual use. For this reason, that study suggested that health care providers should offer family counseling and a stronger evidence about the long-term impact of screen use. ${ }^{6}$

According to the National Survey on Cultural Consumption and Digital Environment of 2017, which focused on cultural consumption and habits among individuals older than 13 years, $95.3 \%$ of them watched TV for an average of 3.5 hours per day. ${ }^{10}$ Also, $76 \%$ of them accessed the Internet through a smartphone; $57.1 \%$, through computers, and $13.4 \%$, through tablets. These data were similar to those obtained in young children in our study.

According to the 2017 Science and Technology Technical Report of the National Statistics and Censuses Institute of Argentina (Instituto Nacional de Estadística y Censos, INDEC), corresponding to the Permanent Survey of Households of Argentina, in relation to the characteristics of access to technology at home and its use in the population older than 4 years, $81.2 \%$ used a smartphone; in our study, this corresponded to $80 \%$. Such information is relevant because our population included children younger than 4 years. ${ }^{11}$

The adaptation of Common Sense Media's 2013 nationwide survey, conducted in Pennsylvania, which included 350 children aged between 6 months and 4 years, revealed the presence of TV in $97 \%$ of households, tablets in $83 \%$, smartphones in $77 \%$, and computers in $58 \% .^{12}$ Mobile device use accounted for $96.6 \%$ and the age at beginning was before 1 year old in
$43.5 \%$. That population was closer in age to ours, and results were similar.

A cohort study conducted in Sydney, which included 500 children, recorded that exposure time at 18 months old was more than 2 hours per day in $40 \%$ of children, consistent with the results of our study. ${ }^{13}$ At 2 years old, children had the ability to unlock, slide, and interact purposefully with touchscreen devices (according to a survey administered to the parents of 82 children aged between 12 months and 3 years). ${ }^{14}$

The American Academy of Pediatrics has developed an online strategy to provide family counseling about media consumption based on children's age. ${ }^{15}$ The main characteristics of an educational format include an interaction to trigger reactions in children based on their own actions, adapted by age and preferences, with progressive complexity as strategies are acquired and the promotion of joint attention. ${ }^{16} \mathrm{In}$ relation to the quality of videos and games used in devices, three quarters of our population were exposed to at least one non-educational format.

The data of our study allow us to infer that when parents consider that the early introduction of screen use has a harmful effect on development, they tend to implement more restrictions in the average exposure time (1.8 versus 2.25 hours per day). Likewise, it was observed that the parents of children with a longer average exposure time (2.92 hours per day) are those who expressed concern about psychomotor development disorders in their children.

The finding of parental concern about psychomotor development is a risk indicator. The probability of actual alterations is $80 \%$, and such finding requires a detailed clinical assessment, the administration of standardized screening tests, and, if applicable, diagnostic and/or ancillary tests for a timely intervention. ${ }^{4,5}$ It is worth noting that technology use in accordance with the recommendations made by the Sociedad Argentina de Pediatría helps to encourage learning through educational applications and e-book reading. ${ }^{2}$

A strength of this study is that the results are similar to those obtained in the National Survey on Cultural Consumption and Digital Environment of 2017, ${ }^{10}$ the INDEC's Science and Technology Technical Report of 2017,11 and the adaptation of Common Sense Media's 2013 nationwide survey, ${ }^{12}$ and reinforce the need to work together with parents to approach this problem during office visits. A weakness of this study was that the age distribution of our sample 
was not homogeneous because it included a greater proportion of parents of children aged between 2 years and 3 years, 11 months, 29 days than of children aged between 18 months and 23 months, 29 days.

As Winnicott has once reflected, playing is always a creative experience for children. In playing, they can create, use their whole personality, and even discover their self by representing themselves as creators. ${ }^{17}$

\section{CONCLUSIONS}

One-hundred percent of children use some of the devices in combination. Based on our results, parental concern about psychomotor development alterations arises when young children's exposure to technology exceeds the current recommendations for age.

\section{REFERENCES}

1. Boyle CA, Boulet S, Schieve LA, Cohen RA, et al. Trends in thePrevalence of Developmental Disabilities in USChildren, 1997-2008. Pediatrics. 2011; 127(6):1034-42.

2. SubcomisióndeTecnologíasdeInformacióny Comunicación de la Sociedad Argentina de Pediatría. Bebés, niños, adolescentes y pantallas: ¿qué hay de nuevo? Arch Argent Pediatr. 2017; 115(4):404-8.

3. Council on Communications and Media. Media and Young minds. Pediatrics. 2016; 138(5):e20162591.

4. Delahunty C. Developmental delays and autism: screening and surveillance. Cleve Clin J Med. 2015; 82(11 Suppl 1): S29-32.

5. Comité de Crecimiento y Desarrollo de la Sociedad Argentina de Pediatría. Guía para el seguimiento del desarrollo infantil en la práctica pediátrica. Arch Argent Pediatr. 2017; 115(Supl 3):s53-62.

6. Melamud A, Waisman I. Pantallas: discordancias entre las recomendaciones y el uso real. Arch Argent Pediatr. 2019; 117(5):349-51.
7. Waisman I, Hidalgo E, Rossi M. Uso de pantallas en niños pequeños en una ciudad de Argentina. Arch Argent Pediatr. 2018; 116(2):e186-95.

8. Necuzzi C. Los modos de aprendizaje en entornos tecnológicos. In: Necuzzi C. Estado del arte sobre el desarrollo cognitivo involucrado en los procesos de aprendizaje y enseñanza con integración de las TIC. Buenos Aires: UNICEF; 2013:8688. [Accessed on: February $5^{\text {th }}, 2018$ ]. Available at: https: / campuseducativo.santafe.edu.ar/wp-content/ uploads / adjuntos / recursos / 20160719202258Estado_arte_ desarrollo_cognitivo.pdf.

9. Kelly V.Primera Infancia frente a las pantallas: de fenómeno social a asunto de estado. CuadernoSITEAL. Buenos Aires: IIPE.UNESCO; 2016. [Accessed on: February 5 ${ }^{\text {th }}, 2018$ ] Available at: http:/ / www.tic.siteal.iipe.unesco.org/sites/ default/files/stic_publicacion_files/tic_cuaderno_pantallas. pdf.

10. Catalano F, Kunst M, Mancinelli E, Pérez L, et al. ¿Qué miramos? ¿Qué leemos? ¿Qué hacemos en internet? In: Encuesta Nacional de Consumos Culturales 2017. Buenos Aires: SINCA. Ministerio de Cultura; 2017; 15-34. [Accessed on: February $\left.5^{\text {th }}, 2018\right]$. Available at: https: / / www.cultura.gob. ar/media/uploads/encc_2017_informe_general.pdf.

11. Villelli M, Paoloni P, Duclós S. Acceso y uso de tecnologías de la información y la comunicación. EPH. Cuarto trimestre 2017. Ciencia y Tecnología. 2018;2(1):3. [Accessed on: June 11 $\left.{ }^{\text {th }}, 2018\right]$. Available at: https://www.indec.gob.ar/ uploads/informesdeprensa/mautic_05_18.pdf.

12. Kabali HK, Irigoyen MM, Nunez-Davis R, Budacki JG, et al. Exposure and use of mobile media devices by young children. Pediatrics. 2015; 136(6):1044-50.

13. Chandra M, Jalaludin B, Woolfender S, Descallar J, et al. Screen time of infants in Sydney, Australia: a birth cohort study. BMJ Open. 2016; 6(10):e012342.

14. Ahearne $C$, Dilworth $S$, Rollings R, Livingstone V, et al. Touch-screen technology usage in toddlers. Arch Dis Child. 2016; 101(2):181-3.

15. American Academy of Pediatrics. Plan para el consumo mediático desu familia. Illinois, 2016. [Accessed on:February $\left.5^{\text {th }}, 2018\right]$. Available at: https: / / www.healthychildren.org/ spanish/media/paginas/default.aspx.

16. GoldfarbG. Bebés, niños, adolescentesy pantallas. InSociedad Argentina de Pediatría. PRONAP. 2016; 3(4):123-38.

17. Winnicott, D. Realidad y juego. $2 .{ }^{\text {nd }}$ ed. Barcelona: Gedisa; 1971. 


\section{ANNEX}

Survey

1. Sex of the child: FEMALE/MALE

2. Age in months:

3. Does the child use a computer?: YES/NO

4. Does the child use a tablet?: YES/NO

5. Does the child use a mobile phone?: YES/NO

6. To watch videos?: YES/NO

7. To watch educational videos?: YES/NO/SOMETIMES

8. To watch non-educational videos?: YES/NO/SOMETIMES

9. To play games?: YES/NO

10. To play educational games?: YES/NO/SOMETIMES

11. To play non-educational games?: YES/NO/SOMETIMES

12. Does the child use the device on their own?: YES/NO

13. Does the child use the device with an adult?: YES/NO/SOMETIMES

14. Does the child use the device before going to bed?: YES / NO

15. Does the child watch TV?: YES/NO

16. Does the child watch cartoons?: YES/NO

17. Other?: YES/NO

18. During meal time, such as lunch and dinner, is the TV on?: YES/NO

19. Does the child have a TV in their bedroom?: YES/NO

20. Does the child use non-technological, educational toys, such as dough, building blocks, puzzles, etc.?: YES / NO

21. Does the child have stories read to them?: YES/NO

22. Does the child play with other kids their age?: YES/NO

23. Does the child play with their parents?: YES/NO

24. Does the child attend daycare?: YES/NO

25. Who looks after the child during the day?: Mother/father/ both/baby-sitter/other caregiver

26. Does the child play outdoors?: YES/NO

27. How many hours in total does the child spend using a mobile phone, tablet, computer and/or TV?

28. Do you think using technology favors your child's psychomotor development?: YES/NO

29. Do you think using technology is harmful for your child's psychomotor development?: YES/NO

30. Do you have any concern about your child's psychomotor development?:

YES/NO

WHAT IS IT? 